\title{
Using of Open Biopsy Microseparator in the Fresh Cadaveric Cow Brain for the Evaluation of Clinical Usability
}

Sir,

The aim of this experimental study was to evaluate the feasibility of open biopsy microseparator in the protection of brain tissue ${ }^{[1]}$ from the harmful mechanical effect of metallic microsurgical instruments and easily obtaining of biopsy.

It was created an experimental microneurosurgical model using fresh cadaveric uncovered cow brain in the evaluation of the efficacy of open biopsy separator [Figure 1]. The appearance of separator is shown in Figure 1. The cow brains were equally divided into two groups as open biopsy microseparator (Group I) and microscissor, aspirator, and microbayonet group (Group II). In Group I, $1 \mathrm{~cm}$ arachnoid and pia mater incision was done on the left side of the brain hemisphere just $2 \mathrm{~cm}$ lateral to the interhemispheric fissure. Three centimeters in length, open biopsy microseparator was placed with $45^{\circ}$ angle to deep into the brain [Figure 2]. The application of microsurgical separator is shown in Figure 2. Biopsy was obtained using biopsy forceps from anterior, medial, posterior,

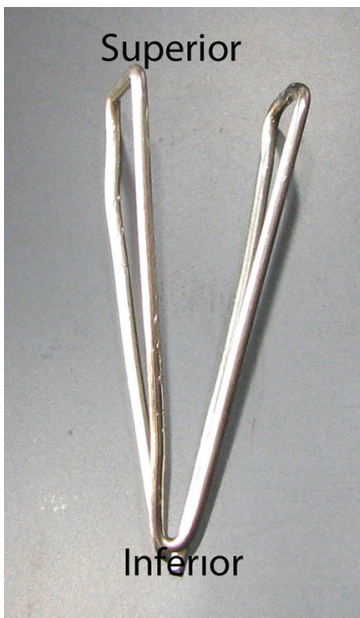

Figure 1: In this figure the shape of the instrument was shown (Superior: the superior site of the instrument, inferior: the inferior site of the instrument)

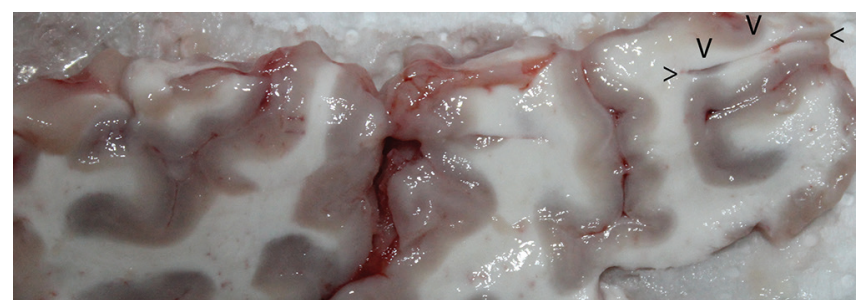

Figure 3: The brain appearance of minor injury after biopsy processing with microsurgical separator (arrows show the biopsy site) and lateral site. The right side of the brain hemispheres was kept as control side. In Group II, $3 \mathrm{~cm}$ deep location was reached through microdissection and separation using microbayonet, microscissor, and the metallic tip of the aspirator before obtaining the biopsy material. After reaching the adequate deepness, the biopsy was performed at the similar places. Following the experiment, all operated brains were sliced regularly $(0.5 \mathrm{~cm})$ from anterior to posterior direction for the evaluation of the harmful effects of the metallic instruments to the brain parenchyma. All brain slices were evaluated under the magnification of the operating microscope in terms of contusion, tearing, distortion, and other traumatic features. The mechanical traumatic effects were divided into three groups as minor, moderate, and severe. The comparisons were done with the opposite side (unoperated right side).

In Group I $(n=15)$, the number of minor injured brains was found as nine $(60 \%)$. The appearance of

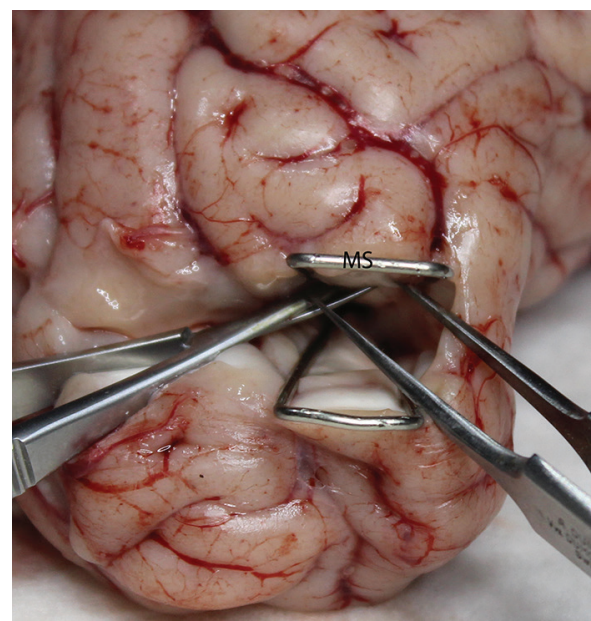

Figure 2: The using of instrument was shown in this figure (MS: Microseparator)

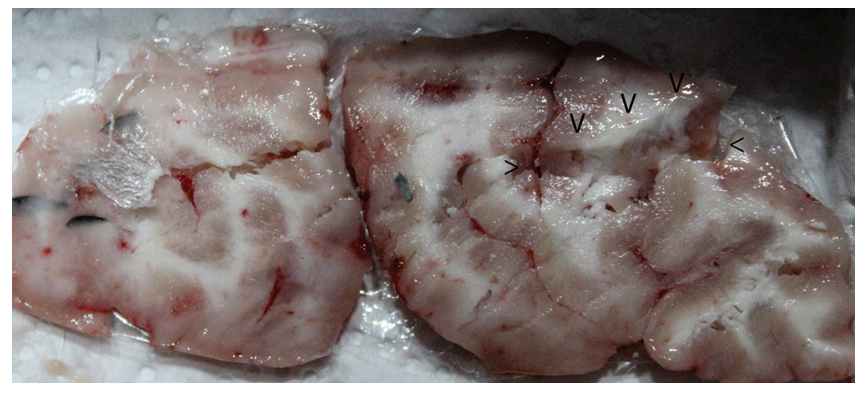

Figure 4: The brain appearance of severe injury after biopsy processing with microsurgical technique without microsurgical biopsy separator (arrows show the biopsy site) 
minor injured brain in Group I was shown in Figure 3. In Group II $(n=15)$, the minor injured brains' number was found as $2(13.33 \%)$. On the other hand, the number of moderately injured brains' parenchyma in Group I cow brain was estimated as 5 (33.33\%). Despite that, the number of moderately injured brains in Group II was found as $9(60 \%)$. The number of severe injury was found as $4(26.67 \%)$ in Group II. The severe injury of Group II cow brain was shown in Figure 4. The number of same injury was found as $1(6.67 \%)$ in Group I.

In conclusion, easily performing the biopsy procedure and protecting of the brain tissue with use of open biopsy separator are feasible as shown in this experimental study.

\section{Financial support and sponsorship}

Nil.

\section{Conflicts of interest}

There are no conflicts of interest.

Department of Neurosurgery, Faculty of Medicine, Ondokuzmayis University, Samsun, Turkey
Address for correspondence: Prof. Cengiz Cokluk, Department of Neurosurgery, Faculty of Medicine, Ondokuzmayis University, Samsun, Turkey.

E-mail: cengizcokluk@yahoo.com

\section{REFERENCE}

1. Cokluk C, Aydin K. Maintaining microneurosurgical ability via staying active in microneurosurgery. Minim Invasive Neurosurg 2007;50:324-7.

This is an open access article distributed under the terms of the Creative Commons Attribution-NonCommercial-ShareAlike 3.0 License, which allows others to remix, tweak, and build upon the work non-commercially, as long as the author is credited and the new creations are licensed under the identical terms.

\begin{tabular}{|l|l|}
\hline \multicolumn{2}{|c|}{ Access this article online } \\
\hline Quick Response Code: & Website: \\
\hline
\end{tabular}

How to cite this article: Cokluk C. Using of open biopsy microseparator in the fresh cadaveric cow brain for the evaluation of clinical usability. J Neurosci Rural Pract 2017;8:485-6.

(c) 2017 Journal of Neurosciences in Rural Practice | Published by Wolters Kluwer - Medknow 